\title{
Characterization of a Discontinuous Epitope of the HIV Envelope Protein gp120 Recognized by a Human Monoclonal Antibody Using Chemical Modification and Mass Spectrometric Analysis
}

\author{
Christine Hager-Braun, ${ }^{a}$ Elisabeth O. Hochleitner, ${ }^{\mathrm{a}, *}$ \\ Miroslaw K. Gorny, b Susan Zolla-Pazner, ${ }^{\mathrm{b}}$ Rachelle J. Bienstock, ${ }^{\mathrm{a}}$ and \\ Kenneth B. Tomer ${ }^{\mathrm{a}}$ \\ a Laboratory of Structural Biology, National Institute of Environmental Health Sciences, National Institutes of \\ Health, Department of Health and Human Sciences, Research Triangle Park, North Carolina, USA \\ ${ }^{\mathrm{b}}$ New York University School of Medicine and Veterans Affairs New York Harbor Healthcare System, New \\ York, New York, USA
}

A subset of the neutralizing anti-HIV antibodies recognize epitopes on the envelope protein gp120 of the human immunodeficiency virus. These epitopes are exposed during conformational changes when gp120 binds to its primary receptor CD4. Based on chemical modification of lysine and arginine residues followed by mass spectrometric analysis, we determined the epitope on gp120 recognized by the human monoclonal antibody 559/64-D, which was previously found to be specific for the CD4 binding domain. Twenty-four lysine and arginine residues in recombinant full-length glycosylated gp120 were characterized; the relative reactivities of two lysine residues and five arginine residues were affected by the binding of 559/64-D. The data show that the epitope is discontinuous and is located in the proximity of the CD4-binding site. Additionally, the reactivities of a residue that is located in the secondary receptor binding region and several residues distant from the CD4 binding site were also altered by $\mathrm{Ab}$ binding. These data suggest that binding of 559/64-D induced conformational changes which result in altered surface exposure of specific amino acids distant from the CD4-binding site. Consequently, binding of 559/64-D to gp120 affects not only the CD4binding site, which is recognized as the epitope, but appears to have a global effect on surface exposed residues of the full-length glycosylated gp120. (J Am Soc Mass Spectrom 2010, 21, 1687-1698) ( 2010 Published by Elsevier Inc. on behalf of American Society for Mass Spectrometry

S hortly after infection with the human immunodeficiency virus (HIV-1), patients develop antibodies (Abs) against the virus; however, ultimately the immune system fails to control the virus, leading to acquired immune deficiency syndrome (AIDS). The characterization of neutralizing antibodies, which are generated by most individuals infected with HIV and are a major component of host defense against the virus, will provide insight on the structural features of antigenrecognition and the development of neutralization resistance. HIV neutralizing antibodies are mainly directed against the transmembrane protein gp41 and the envelope protein gp120 [1, 2]. Both gp41 and gp120 are expressed as the precursor protein gp160, which matures into the

Address reprint requests to Dr. K. B. Tomer, National Institute of Environmental Health Sciences, NIH, DHHS, Laboratory of Structural Biology, Building 101, MD F0-03, 111 T. W. Alexander Drive, Research Triangle Park, NC 27709, USA. E-mail: tomer@niehs.nih.gov

* Current address: Consortium für Elektrochemische Industrie, Wacker Chemie, Zielstattstrasse 20, D-81379 Munich, Germany. individual proteins by cleavage. The proteins remain noncovalently associated and form a trimeric oligomer $(g p 41 / g p 120)_{3}$ [3]. During the initial step of infection, a noncovalent complex is formed between gp120 and its primary receptor $\mathrm{CD} 4$, which is located as a transmembrane glycoprotein on circulating CD4 lymphocytes and monocytes $[4,5]$. Subsequently, conformational changes occur in gp120 and CD4, which expose the binding site on the surface of gp120 for a coreceptor of the chemokine receptor family. After formation of the complex of gp120/ CD4/coreceptor, additional conformational changes in gp41 occur, facilitating the fusion of the viral membrane with the host cell membrane and entry of the viral RNA into the cell [6, 7].

Homology analyses of the glycoprotein gp120 have identified five conserved regions and five variable regions [8]. The conserved regions form the core of the protein (the core consists of Gly-Ala-Gly tripeptide substitutions for $67 \mathrm{~V} 1 / \mathrm{V} 2$ loop residues and 32 V3 loop residues; and the removal of all sugar groups beyond
(C) 2010 Published by Elsevier Inc. on behalf of American Society for Mass Spectrometry. $1044-0305 / 10 / \$ 32.00$

doi:10.1016/j.jasms.2010.03.031
Published online March 31, 2010 Received January 21, 2010 Revised February 25, 2010 Accepted March 1, 2010 
the linkages between the two core $\mathrm{N}$-acetylglucosamine residues and deletions of 52 and 19 residues from the $\mathrm{N}$ and C termini, respectively) [9], and disulfide bridges in the variable regions result in the formation of flexible loops [10]. Both conserved and variable regions are extensively glycosylated with $\sim 50 \%$ of the mass of the glycoprotein derived from glycans [10-12]. The variable loops and the carbohydrate moieties on the surface of gp120 shield conserved regions that are functionally important and are only accessible after a sequence of conformational changes in the envelope protein. Nevertheless, several regions are targets for neutralizing antibodies, in particular the variable loops V1/V2 and $\mathrm{V} 3$, the conserved region $\mathrm{C} 4$ (which contains residues involved in CD4-binding), the CD4 binding site (CD4$\mathrm{BS}$, formed by the inner domain, the outer domain and part of the bridging sheet of gp120), and the CD4induced binding site for the coreceptor [13-19]. Mapping of epitopes on gp120, mainly through competition analyses and mutagenic analyses, resulted in the identification of a "neutralizing face" recognized by neutralizing antibodies, a "non-neutralizing face" recognized by non-neutralizing antibodies and a "silent face," which has a very poor immunogenicity due to its extensive glycosylation $[15,20]$. Although a significant number of neutralizing antibodies targeted against epitopes in T-cell line adapted (TCLA) HIV strains have been characterized, only a few antibodies are capable of neutralizing primary HIV isolates in vitro (reviewed in [1, 2, 21].

The reasons for the differences in neutralization sensitivity are not fully understood, but apparently laboratory-adapted viruses and primary isolates adopt different configurations of the trimeric envelope complex [21]. Studies also suggest that various neutralizing antibodies might recognize different conformations of gp120 that do not necessarily correspond to the conformation of the truncated deglycosylated gp120 core in complex with CD4. Analysis of the thermodynamics of gp120-CD4 association showed large enthalpy and entropy changes indicating significant flexibility of gp120 in the unbound form and conformational changes upon binding of the primary receptor [22]. Based on the crystal structure, gp120 in the bound state has a narrow binding pocket for CD4 [9]. Xiang et al. described a gp120 mutant with the amino acid substitution S375W that adopts a narrow conformation at the CD4-BS in the absence of CD4 [23]. This S375W mutant did not bind any of the tested Abs directed against the CD4-BS, also indicating different conformations of the CD4 binding site in absence and presence of the primary receptor. More recently, Kwong and coworkers showed by crystallographic structure determinations that CD4 induces a conformational change in gp120 [24], and that the conformation of the bridging sheet in gp120 undergoes significant conformational change upon CD4 binding [25]. Molecular dynamics simulations also suggest different conformations for gp120 in the bound and unbound states [26]. Recently, the crystal structure of a SIV gp120-core, which represents the unliganded state of the glycoprotein, was published [27]. Comparison of the structure with the liganded $\mathrm{HIV}_{\mathrm{HXBc} 2}$ gp120-core showed significant conformational differences of the inner domain. In the unliganded conformation, the constituents of the CD4-binding domain form a cavity, which is long and narrow compared with the open cavity in the CD4-bound HIV-gp120.

Here we present the mapping of the epitope of full-length, non-deglycosylated gp120 recognized by the human monoclonal antibody (MAb) 559/64-D by chemical modification of arginine (R) and lysine (K) residues and subsequent mass spectrometric analyses. Immunochemical studies suggested that the epitope of this MAb is located in the CD4-BS [28], and functional studies show that this MAb is able to neutralize several TCLA-adapted strains of HIV [29]. Interestingly, this and other MAbs to the CD4-binding site have been shown to prevent proteolysis of gp120 and subsequent presentation of gp120 to CD4-T-cells [30-33] that sera with broadly cross-neutralizing Abs have anti-CD4-BS Abs, which can be responsible or contribute to the breadth of neutralization [34, 35]. MAb 559/64-D may also have characteristics similar to the anti-CD4-BS MAb F105, which is often used in many studies and is also not broadly neutralizing for non-TLCA strains [36]. The CD4-BS is conserved among HIV strains and is functionally required for the initial step of infection. Consequently, it is important to determine the binding site of neutralizing and non-neutralizing Abs such as the MAb 559/64-D targeting the CD4-BS to understand the relationship between gp120-structure and neutralization potency of the Abs.

In this study, gp120 bound to the antibody 559/64-D, as well as free in solution, was modified by either lysine acetylation or arginine hydroxyphenylglyoxylation, and differences in the modification pattern were used to indicate interaction sites between the antibody and its antigen. The acetylation of the $\varepsilon$-amino group at the $\mathrm{N}$-terminus of a protein and of the $\alpha$-amino group in lysine residues has been previously used to characterize the topology of proteins [37-40]. The derivatization of arginine residues with hydroxyphenylglyoxal (HPG) has been established as a modification to determine the participation of arginines in the active site of proteins and in the interaction site with a binding partner [41, 42]. In the present case, observed differences in reactivity of arginines and lysines are used as a measure of the accessibility of the residue to the reagent. It should be noted that this is not identical to surface accessibility as changes in reactivity resulting from, for example changes in $\mathrm{pK}_{\mathrm{a}}$ due to variations in residue reactivities (e.g., salt bridges) are eliminated by taking the ratio of reactivity in the bound and unbound states.

\section{Experimental}

\section{Materials}

The CHO-cell expressed glycoprotein gp120 from HIV strain SF2 was purchased from Austral Biologicals (San 
Ramon, CA, USA). The monoclonal antibody (MAb) 559/64-D was produced as described in Karwowska et al. [29]. Endoproteinases GluC, AspN, and LysC were obtained from Roche Molecular Biologicals (Indianapolis, IN, USA), trypsin-(tosyl-amido-2-phenyl) ethylchloromethyl ketone from Worthington Biochemical (Freehold, NJ, USA) and PNGaseF from Roche Diagnostics (Mannheim, Germany) and Glyko (Novato, CA, USA). Hydroxyphenylglyoxal was obtained from Pierce (Rockford, IL, USA), iodoacetamide and $\alpha$-cyano-4hydroxycinnamic acid from Aldrich (Milwaukee, WI, USA), and acetic anhydride and hexadeuteroacetic anhydride from Sigma (St. Louis, MO, USA).

\section{Derivatization of Lysine Residues}

HIV-gp120 and the MAb 559/64-D were combined and incubated for $1 \mathrm{~h}$ at RT. A 2-fold molar excess of the MAb compared to gp120 was used to assure that all gp120 was bound to the antibody based on the dissociation constant of the complex $\left(14 \times 10^{-9} \mathrm{M}\right)$ [29]. The molar excesses that are necessary for the partial and the complete acetylation of gp120 were determined by acetylation of the protein with 1000-, 10,000-, and 200,000-fold molar excess and subsequent purification by reversed-phase HPLC. The conditions were as follows: protein-C4-column $(4.6 \mathrm{~mm} \times 250 \mathrm{~mm}$; Vydac, Hesperia, CA, USA) with a C4-guard column (Vydac); flow rate $1 \mathrm{~mL} / \mathrm{min}$; $\mathrm{A}: 0.1 \%$ trifluoroacetic acid in water, B: $0.09 \%$ trifluoroacetic acid, $10 \%$ water in acetonitrile; gradient $10 \% \mathrm{~B}$ to $70 \%$ B over $50 \mathrm{~min}$; 1 $\mathrm{mL}$-fractions. The collected fractions were lyophilized, re-dissolved in PBS, and analyzed by matrix-assisted laser desorption/ionization (MALDI) mass spectrometry (MS). The purified protein was digested with the endoproteinase GluC in $50 \mathrm{mM}$ NH4HCO3 buffer at $37{ }^{\circ} \mathrm{C}$ and analyzed by MALDI/MS. Acetylated peptides were identified by their mass shift of $42 \mathrm{Da}$. A 1000-fold and a 10,000-fold molar excess, respectively, led to partial acetylation of gp120. With a molar excess of 200,000, complete acetylation was observed. Note that the molar excess does not include the aqueous environment, which also reacts with acetic anhydride, albeit at a slower rate than does the primary amine. To ensure that the antigen-antibody complex remains intact during modification, the antibody was immobilized on cyanogen bromide-activated Sepharose beads (Pierce Chemical Co. Rockford, IL, USA) as described previously [38], gp120 was added, and the Ab-Ag complex was formed by incubation for $1 \mathrm{~h}$ at RT. Subsequently, the beads were washed to remove any unbound protein and analyzed by MALDI/MS for the presence of bound gp120. The complex was then acetylated with 10,000fold molar excess acetic anhydride and washed again. The subsequent analysis of the beads by MALDI/MS showed that the acetylated gp120 was still affinitybound.

For differential modification of lysine residues, the antigen-antibody complex in solution was initially acetylated with a 10,000-fold molar excess of acetic anhydride. Under these conditions, the native conformation of the protein was largely retained as indicated by continued recognition by the antibody. The acetylated gp120/MAb complex was purified by reversedphase HPLC. Fractions containing the acetylated gp120 were combined and derivatized with a 200,000-fold molar excess of hexadeuteroacetic anhydride. Under these conditions, the protein became denatured, allowing exhaustive acetylation. Acetylated residues were accessible to the reagent in the native or complexed state, while deuteroacetylated residues became accessible to the reagent only after denaturing the protein, regardless of whether the protein was initially complexed or non-complexed. The acetylated/trideuteroacetylated protein was again purified by HPLC. After lyophilization,

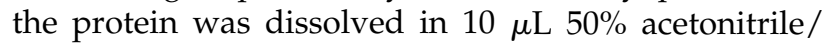
$0.1 \%$ formic acid. The solution was diluted $1: 5$ with 50 $\mathrm{mM}$ ammonium bicarbonate $(\mathrm{pH} 8.3)$ and digested with endoproteinase GluC (enzyme:substrate ratio 1:20) for $12 \mathrm{~h}$ at $37^{\circ} \mathrm{C}$. The solution was split into two equal parts. One part was digested further with trypsin for $4 \mathrm{~h}$ at $37^{\circ} \mathrm{C}$ (enzyme:substrate ratio 1:20). The peptides in both samples were deglycosylated with PNGaseF for $12 \mathrm{~h}$ at $37^{\circ} \mathrm{C}$. To reduce and alkylate the disulfide bridges, DTT was added to a final concentration of 10 $\mathrm{mM}$ (ca. 25:1 M ratio of DTT per disulfide bond), and the solution was incubated at $56{ }^{\circ} \mathrm{C}$ for $1 \mathrm{~h}$. The peptides were alkylated with $55 \mathrm{mM}$ iodoacetamide for $45 \mathrm{~min}$ at $56{ }^{\circ} \mathrm{C}$ in the dark. Subsequently, the samples were analyzed by MALDI/MS and liquid chromatography (LC) electrospray ionization (ESI) MS/MS. All reactions were performed in duplicate. The ratio of deuteroacetylated lysine containing peptide to non-deuteroacetylated lysine containing peptide was determined from the abundances of the extracted ion currents of the protonated molecules.

\section{Derivatization of Arginine Residues}

For the formation of a noncovalent complex, HIV-gp120 and the MAb 559/64-D were incubated for $2 \mathrm{~h}$ at RT in a 2:1 ratio with a final concentration of 3 pmol gp120/ $\mu \mathrm{L}$. Arginine residues were derivatized with $10 \mathrm{mM}$ HPG in $25 \mathrm{mM} \mathrm{NaHCO} 3$ for $18 \mathrm{~h} 30 \mathrm{~min}$ with rotation at RT in the dark. As a control, gp120 was incubated with $10 \mathrm{mM} \mathrm{HPG}$ in the absence of the MAb. After derivatization, gp120 was purified from the antibody and the excess HPG by reversed-phase HPLC. The conditions were as follows: protein-C4-column (4.6 $\mathrm{mm} \times$ $250 \mathrm{~mm}$; Vydac, Hesperia, CA, USA) with a C4-guard column (Vydac); flow rate $1 \mathrm{~mL} / \mathrm{min}$; A: $0.1 \%$ trifluoroacetic acid in water, B: $0.1 \%$ trifluoroacetic acid in acetonitrile; gradient: $2 \% \mathrm{~B}, 5 \mathrm{~min} ; 2 \% \mathrm{~B}$ to $95 \% \mathrm{~B}, 50$ min; $95 \%$ B, 5 min; collection of $1 \mathrm{~mL}$ fractions. After lyophilization, the protein in each fraction was resuspended in $5 \mu \mathrm{L} \mathrm{50 \%}$ acetonitrile $/ 0.1 \%$ formic acid and analyzed by MALDI/MS. Fractions containing derivatized gp120 were combined. Multiple reactions and 
digestion conditions were performed at different times. Due to limited MAb availability, only single derivatizations under each set of conditions could be performed.

To determine the sites of derivatization, HPG-modified gp120 was digested with various endoproteinases. A 100 pmol aliquot of modified gp120 was diluted 10-fold to give a concentration of $5 \%$ acetonitrile and then incubated with endoproteinase LysC at a ratio of 1:20 in $25 \mathrm{mM}$ Tris- $\mathrm{HCl}\left(\mathrm{pH} \mathrm{8.0)}\right.$ ) for $18 \mathrm{~h}$ at $37^{\circ} \mathrm{C}$. The peptides were deglycosylated with PNGaseF for $24 \mathrm{~h}$ at $30^{\circ} \mathrm{C}$. Additionally, an aliquot of the deglycosylated LysC digest was further digested with the endoproteinase AspN at an enzyme:substrate ratio of 1:62.5 for $18 \mathrm{~h}$ at $35^{\circ} \mathrm{C}$. Equivalent changes in reactivity were observed for specific residues determined from different reactions and digested with different reagents.

\section{MALDI/MS}

Mass spectra were acquired on a Voyager DE-STR Super MALDI time-of-flight instrument (Applied Biosystems, Framingham, MA, USA). $\alpha$-Cyano-4-hydroxycinnamic acid was re-crystallized in hot methanol and stored in the dark. Before analysis of acetylated proteins and peptides, a fresh solution of saturated $\alpha$-cyano-4hydroxycinnamic acid in water/ethanol/formic acid 45/45/10 ( $\mathrm{vol} / \mathrm{vol}$ ) was prepared. Matrix solution (0.5 $\mu \mathrm{L})$ was mixed with sample $(0.5 \mu \mathrm{L})$, pipetted onto the target and dried at RT. Mass calibration was performed using an external calibrant (Applied Biosystems).

\section{LC-ESI/MS and MS/MS}

For the LC-ESI/MS analyses, an aliquot of the acetylated peptide sample was injected onto a Hypersil RP-18 column (75 $\mu$ m i.d. $\times 15 \mathrm{~cm}$; LC Packings, San Francisco, CA, USA) and eluted with a linear gradient of $5 \%$ to $95 \%$ B in 30 min (A: $0.1 \%$ formic acid in water, B: $0.1 \%$ formic acid in acetonitrile). The solvents delivered from the pumps were split before the sample injector such that $200 \mathrm{~nL} / \mathrm{min}$ were delivered to the mass spectrometer.

Separation of HPG-derivatized peptides from an 8 $\mu \mathrm{L}$-aliquot, which had been incubated with $5 \mathrm{mM}$ dithioerythritol for $30 \mathrm{~min}$ at RT before analysis, was achieved on a C18-PepMap column (5 $\mu \mathrm{m}, 75 \mu \mathrm{m}$ i.d. $X$ $150 \mathrm{~mm}$, LC Packings); conditions: A: $0.1 \%$ formic acid in water; B: $0.1 \%$ formic acid in acetonitrile; gradient: 0.3 $\mu \mathrm{L} / \mathrm{min} ; 5 \% \mathrm{~B}, 5 \mathrm{~min} ; 5 \%-95 \%$ B over $35 \mathrm{~min}$.

For online analysis of the eluting peptides, the nanoHPLC column was connected to an electrospray ionization source on a quadrupole-time-of-flight instrument (QTOF-I and QTOF-Micro, Micromass, Altrincham, UK). Instrument conditions for QTOF-I: capillary 2800$3095 \mathrm{~V}$, sample cone $19-21 \mathrm{~V}$, source temperature $80^{\circ} \mathrm{C}$, scan: MS, $m / z$ 300-4000 over $2 \mathrm{~s}$, MS/MS, $m / z$ 50-2000 over 2 s, collision energy $30 \mathrm{~V}$. Conditions on QTOFMicro for MS: capillary voltage $3000 \mathrm{~V}$, cone voltage 30 $\mathrm{V}$, extraction voltage $2.5 \mathrm{~V}$, collision energy $10 \mathrm{~V}$, source temperature $20{ }^{\circ} \mathrm{C}$, and scan: $m / z \quad 400-1800$ over 0.98 s; alternatively for MS/MS: cone voltage $40 \mathrm{~V}$, collision energy $30 \mathrm{~V}$, scan: $m / z \quad 80-2800$ over 2 s. Data were acquired using MassLynx 3.5 and deconvoluted via MaxEnt3 (Micromass, Altrincham, UK).

\section{Data Analysis}

The relative abundances of HPG-derivatized peptides were calculated from the sum of counts of the peptides in the various charge states, with the total for unmodified and modified peptides defining 100\%. To determine the significance of the relative changes, the ratios of the relative abundance of a specific peptide derived from Ab-bound gp120 to the relative abundance of the corresponding peptide derived from unbound gp120 were calculated. In cases where only one modification state (either modified or unmodified) was observed the relative abundance of this peptide was defined as $99 \%$, whereas the relative abundance of the complimentary peptide (unmodified or modified) was defined as $1 \%$ for calculation purposes only. A ratio of 1 would indicate that the relative reactivity of an arginine residue was equal in the presence and absence of the antibody. The mean of all values was 0.87 with a standard deviation of 0.33 . Data points with a variation from the mean of greater than 1 standard deviation, i.e., R480 and R476, were then omitted. The mean of the remaining data points was calculated to be 0.98 with a standard deviation of 0.14. Based on this standard deviation, ratios within $0.98 \pm 0.14$ indicated no significant change, changes within two standard deviation changes were considered moderately significant, and ratios with greater than \pm 0.28 deviation from the mean were termed significant.

Similarly, the relative reactivity of lysine residues was determined as a ratio of the abundance of acetylated to trideuteroacetylated peptide. To determine changes in reactivity of lysine residues, the ratios of the relative reactivity of gp120 derivatized in the presence of the MAb to the relative reactivity of gp120 in the absence of $\mathrm{MAb}$ were calculated. The reactivity was considered unchanged for ratios with deviations within $\pm 20 \%$ of 1 , moderate for ratios with deviations within $\pm 20 \%$ to $\pm 40 \%$ of 1 and significant for ratios with deviations greater than $\pm 40 \%$.

\section{Residue Numbering System}

The sequence of the HIV-1 $1_{\mathrm{SF} 2}$ gp120 used in this study is shown in Figure 1. The numbering system used is according to Korber et al. [43]. In this system, the sequence of the protein is numbered according to the sequence of the protein in HIV HXB2CG (http:/ / hiv-web.lanl.gov/content/ hiv-db/LOCATE_SEQ/locate.html; http:/ / www.hiv.lanl. gov/content/hiv-db/REVIEWS/HXB2.html). Insertions are indicated as $\times x \times a=A A$ where the inserted amino acid is inserted after residue xxx. If more than one amino acid is inserted, the residues are indicated sequentially 


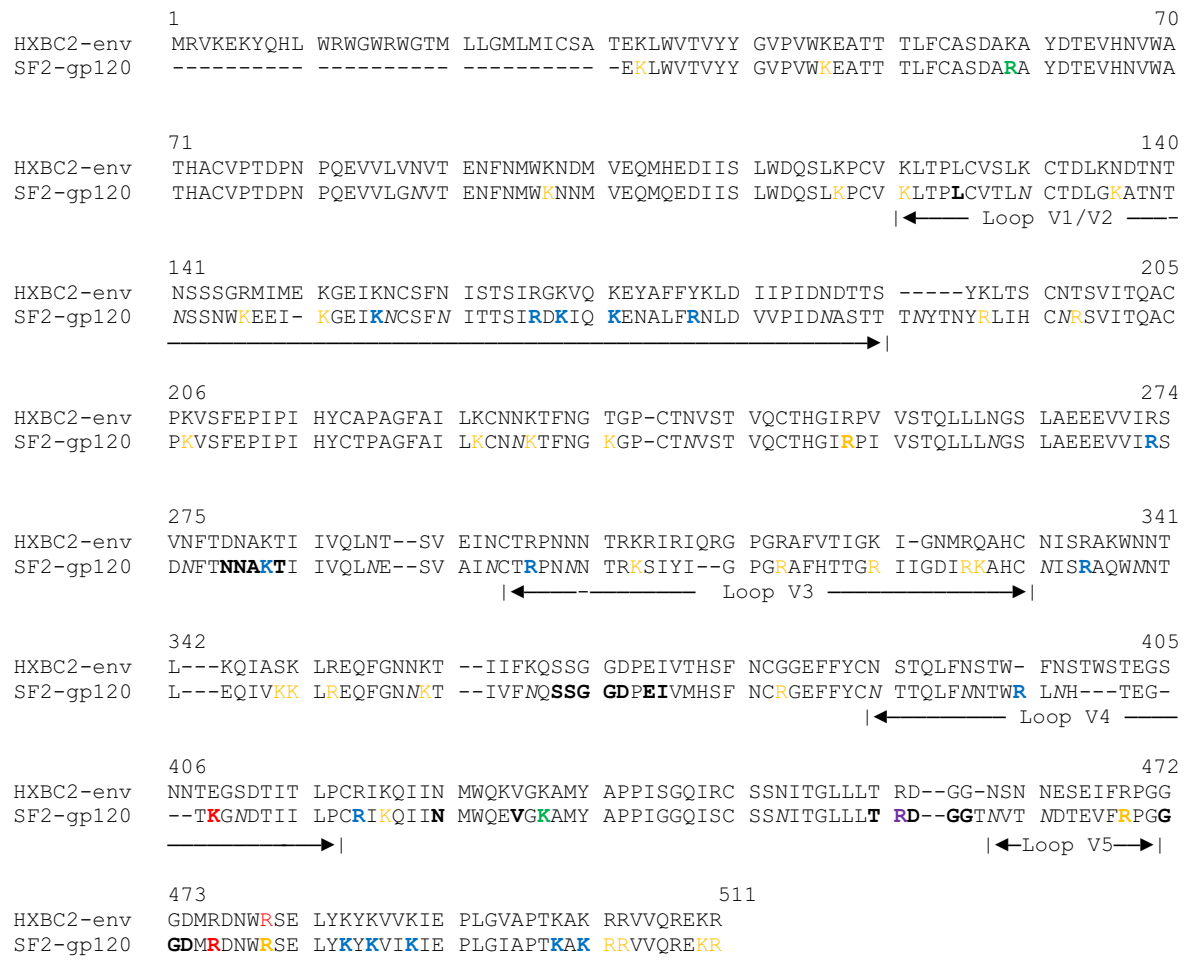

Figure 1. Alignment of the sequences of recombinant HIV-1 $1_{\mathrm{SF} 2}$ gp120 corresponding to amino acids 31-509 of the env-precursor protein [54] and of the residues 1-511 of the reference HXBc2 env-protein [43]. Arginine and lysine residues with a significantly decreased relative reactivity are shown in red, residues with a slightly decreased relative reactivity are shown in purple, residues with no change in relative reactivity in blue, and residues with an increase in relative reactivity are shown in dark-green. Lysine and arginine residues not detected are in orange. N-glycosylation sites in $\mathrm{HIV}_{\mathrm{SF} 2}$ gp120 as determined by mass spectrometry are italicized [11,12]. In the numbering system used here, the annotation " $\Delta 405-407$ " indicates that SF2 gp120 contains a deletion of three residues (405-407) relative to the $\mathrm{HXBc2}$ reference sequence and "ins $459 \mathrm{a}=\mathrm{T}$ " indicates that the SF2 gp120 sequence contains an additional T residue between residues 459 and 460 in the HXBc2 reference sequence [43].

by their single letter designations. AA is the amino acid inserted. Deletions are indicated by HXBC region numbers with deleted amino acid numbers in parentheses, i.e., (del 460-461) or $(\Delta 460-461)$ for deletion of two amino acids at positions 460 and 461 .

\section{Results and Discussion}

To develop a better understanding of the correlation of antigen structure and the neutralization potency of the antibody, it is important to determine the epitope recognized by the antibody using a full-length glycosylated gp120 that closely resembles the wild-type protein. In this study we used non-deglycosylated, non-truncated gp120 from recombinantly expressed HIV strain SF2gp120. To characterize the epitope recognized by the antibody 559/ 64-D, lysine and arginine residues in gp120 were chemically modified and their relative reactivities between gp120 bound to MAb559/64-D and unbound gp120 were determined. The recombinant HIV envelope protein gp120 of HIV strain SF2 is a major representative of the TCLA-strains and corresponds to amino acids 31-509 of the HIVSF2 env-protein. It contains 30 lysine residues and 25 arginine residues (Figure 1).

\section{Lysine Acetylation}

Two acetylation steps were performed, the first with acetic anhydride, and the second, with $\mathrm{d}_{6}$-acetic anhydride. The relative reactivities of the lysine residues for which peptides were observed was determined from the ratios of the abundance of acetylated and trideuteroacetylated peptide, respectively, within one sample. Ratios of the relative reactivity of gp120 derivatized in the presence of the MAb to the relative reactivity of gp120 in the absence of the MAb were used to determine the changes of reactivity upon binding of the MAb 559/64-D (Table 1). The calculation of the ratio of relative reactivities results in a normalization of the relative reactivities, thereby allowing the comparison of the two experimental conditions of gp120 bound to the $\mathrm{MAb}$ and free in solution. The ratio of 1 would indicate that the relative reactivity of a specific residue did not change upon binding of the MAb, while a ratio of 0 
Table 1. Relative reactivities of lysine residues

\begin{tabular}{|c|c|c|c|}
\hline $\begin{array}{l}\text { Lysine } \\
\text { residue }^{a}\end{array}$ & Peptide sequence $\left(\mathrm{HIV}_{\mathrm{SF} 2}\right)$ & $\begin{array}{c}\text { Ratio of modified to } \\
\text { unmodified } \\
\text { in antibody-bound versus } \\
\text { antibody-free HIV-1 gp } 120^{b}\end{array}$ & $\begin{array}{l}\text { Change of } \\
\text { reactivity }\end{array}$ \\
\hline 155 & ${ }^{154}$ IKNCSFNITTSIR $^{166}$ & $1.18 \pm 0.05$ & - \\
\hline 168,171 & ${ }^{167}{ }^{D K I Q K E}{ }^{172}$ & $1.18 \pm 0.1$ & - \\
\hline 282 & ${ }^{270} \mathrm{VVIRSDNFTNNAKTIIVQLNE}{ }^{290}$ & 1.11 & - \\
\hline 305 & ${ }^{305} \mathrm{KSIYIGPGR}^{315} \Delta 310-311$ & $1.16 \pm 0.4$ & - \\
\hline 409 & ${ }^{404}$ GTKGNDTIILPCR ${ }^{419} \Delta 405-407$ & 0 & $\mathbf{s} \downarrow$ \\
\hline 432 & 430VGKAMYAPPIGGQISCSSNITGLLLTRDGGTNVTNDTE ${ }^{466}$ ins $459 a=T$ & 1.56 & $\mathrm{~m} \uparrow$ \\
\hline $\begin{array}{c}485,487,490 \\
500,502\end{array}$ & ${ }^{483}$ LYKYKVIKIEPLGIAPTKAKRRVVQRE ${ }^{509}$ & $1.16 \pm 0.07$ & - \\
\hline
\end{tabular}

aResidue numbers are based on HIVHXBc2 gp120 as shown in Figure 1 (denoted "HXBc2-env").

${ }^{b}$ Ratios of relative reactivity of gp120 derivatized in the presence of the MAb to relative reactivity of gp120 in absence of MAb.

${ }^{\mathrm{c}}$ Reactivity was considered unchanged (-) for ratios with deviations within $\pm 20 \%$ of 1 , moderate (m) for ratios with deviations within $\pm 20 \%$ to $\pm 60 \%$ of 1 , and significant (s) for ratios with deviations greater than $\pm 60 \%$.

indicates greatly reduced access in the presence of the antibody. A ratio of greater than 1.0 indicates increased accessibility/reactivity due to the presence of the MAb.

\section{K409}

Representative LC/ESI/MS spectra of the doublycharged peptide ${ }^{404}$ GTKGNDTIILPCR ${ }^{419 \Delta 405-407}$ after derivatization of lysine residues, deglycosylation, and reductive alkylation of the cysteine residues from the $\mathrm{Ab}-\mathrm{Ag}$ complex and from gp120 free in solution are shown in Figure 2a and b, respectively. The absence of an ion of $\mathrm{m} / \mathrm{z} 744.49$ in the spectrum of acetylated, deglycosylated, and proteolyzed gp120 from the gp120: MAb complex (Figure 2a) shows that, in the presence of the antibody, derivatization of K409 did not occur during the first step but was only achieved under denaturing conditions, resulting in an ion of $m / z 745.94$. In contrast, $\sim 57 \%$ of $\mathrm{K} 409$ was already seen derivatized during the first step of acetylation when the antibody was absent (Figure 2b, Supplemental Figure S-1, which can be found in the electronic version of this article). The relative reactivity of K409 changed from 0.75 for gp120 free in solution to 0 for gp120 bound.

\section{K432}

A ca. 50\% increase in reactivity was observed for this residue in the presence of MAb 559-64D. This increase in reactivity of this residue may indicate that a conformational change occurs in the gp120 in the presence of the antibody that leads to an increased surface accessibility and/or reactivity.
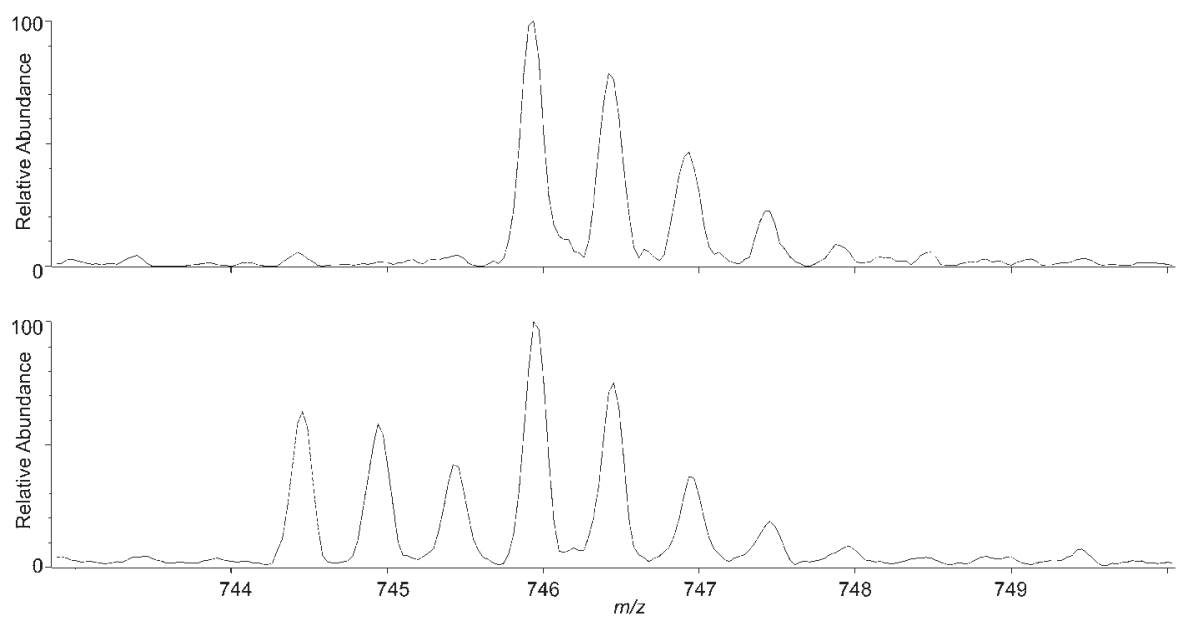

Figure 2. Representative LC/ESI/MS spectra (sum of five individual spectra) of the doubly charged peptide containing residues 404-419 $\Delta 405-407$ with lysine residue 409 derivatized in presence (a) and absence $(\mathbf{b})$ of the MAb. These spectra indicate that K409 was protected from derivatization in the presence of the antibody. 
K155, 168, 171, 282, 305, 485, 487, 490, 500, and 502

The reactivities of these lysines were not affected, within experimental error, by the presence/absence of the antibody. This indicates that the antibody does not interact with these residues.

In summary, of 12 lysine residues that were characterized, the surface reactivity of one residue (K409) was found to be significantly reduced by the presence of $559 / 64-\mathrm{D}$, and the surface reactivity of one residue (K432) was found to be moderately enhanced in the presence of the antibody. Additionally, modifications of residues that lead to change of the formal charge on the residue side chain may also influence the solubility of the modified protein, leading to reduced information about the reactivity of some residues.

\section{Arginine Hydroxyphenyl Glyoxylation}

Arginine residues were modified with hydroxyphenylglyoxal in antibody-bound gp120 and gp120 free in solution. The relative abundances of HPG-derivatized peptides were calculated from the sum of counts of the peptides in the various charge states, with the total for unmodified and modified peptides defining 100\% (Table 2). Representative spectra from an LC/ESI/MS analysis of the triply charged peptide ${ }^{477}$ DNWRSELYK ${ }^{485}$ are shown in Figure 3. R476 was found in peptide 463-476 with
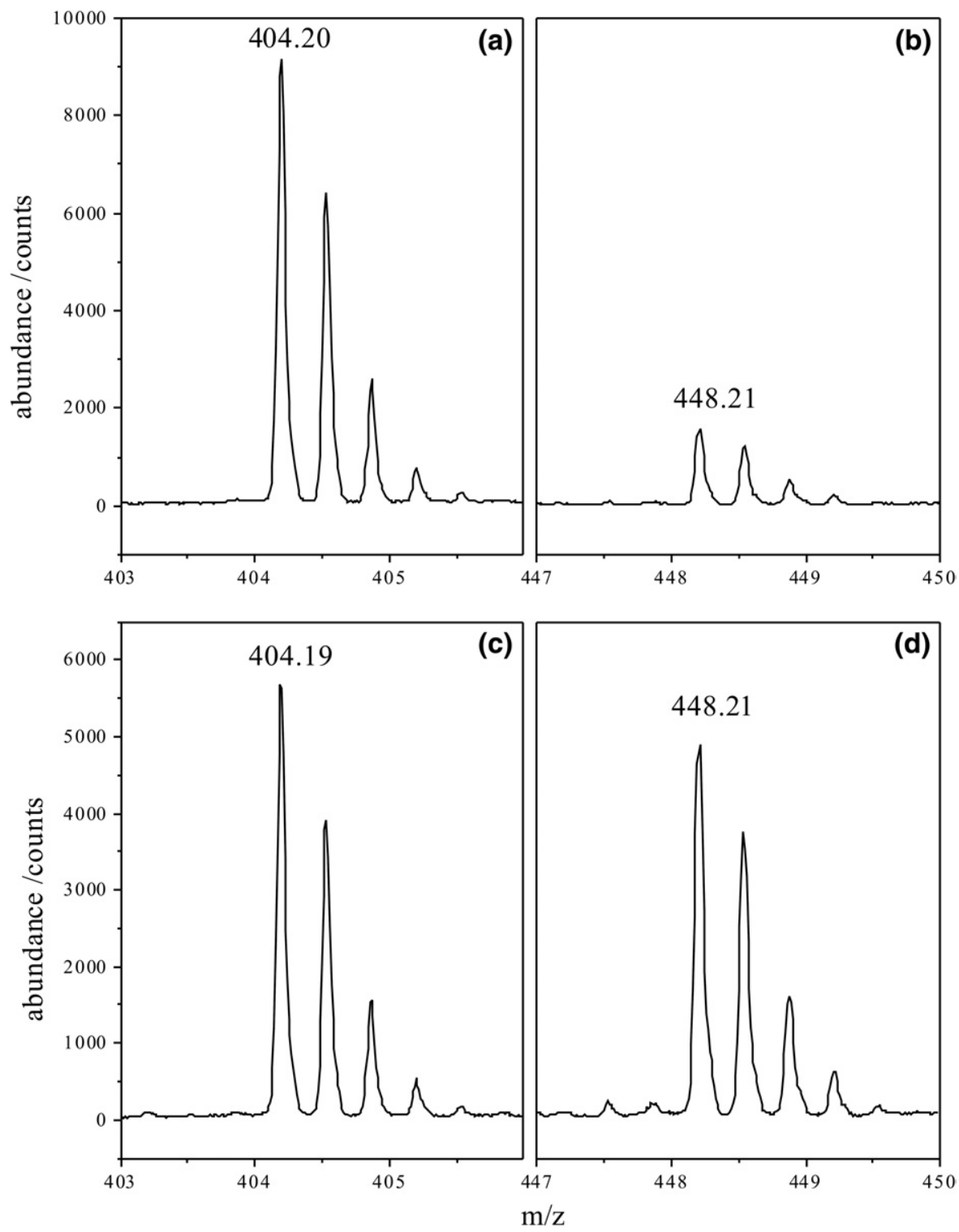

Figure 3. Representative LC/ESI/MS spectra of the triply charged peptide containing residues 477-485 with arginine residue 480 modified in the presence (a) without label, (b) with label, and absence (c) without label, (d) with label) of the MAb. Note that after derivatization with hydroxyphenylglyoxal the retention time of the peptide increases compared to the underivatized peptide. 
Table 2. Relative reactivities of arginine residues ${ }^{\mathrm{c}, \mathrm{d}}$

\begin{tabular}{|c|c|c|}
\hline Arginine residue $^{a}$ & $\begin{array}{l}\text { Ratio of modified to } \\
\text { unmodified in } \\
\text { antibody-bound } \\
\text { versus antibody- free } \\
\text { HIV-1 gp120 }\end{array}$ & Change $^{b}$ \\
\hline $\begin{array}{l}59 \\
{ }^{47} \text { EATTTLFCASDARAY } 61\end{array}$ & 1.11 & $\mathrm{~m} \uparrow$ \\
\hline $\begin{array}{l}166 \\
{ }^{160} \text { NITTSIR }^{166}\end{array}$ & 0.92 & - \\
\hline $\begin{array}{l}177 \\
{ }^{172} \text { ENALFRNL }^{179}\end{array}$ & 0.87 & - \\
\hline $\begin{array}{l}252^{c} \\
237 / 241 \text { GP-TNVST } \\
\text { VQCTHGIRPIVSTQLLL } 261\end{array}$ & 0.81 & $\mathrm{~m} \downarrow$ \\
\hline $\begin{array}{l}273 \\
{ }^{262}{ }^{2} \text { SSLAEEEVVIRS }^{274}\end{array}$ & 1.01 & - \\
\hline $\begin{array}{l}298 \\
{ }^{276} \text { NFTNNAKTI IVOLNE-SV } \\
\quad \text { AINCTRPN }{ }^{300}\end{array}$ & 1.02 & - \\
\hline $\begin{array}{l}335 \\
{ }^{332} \text { NISRAOW }^{338}\end{array}$ & 1.18 & - \\
\hline $\begin{array}{l}\text { 395a } \\
{ }^{392} \text { NNTWRL }^{396 i n s}\end{array}$ & 1.05 & - \\
\hline $\begin{array}{l}419 \\
{ }^{410} \mathrm{GNDTIILPCRIK} \\
421\end{array}$ & 0.95 & - \\
\hline $\begin{array}{l}456^{\mathrm{d}} \\
{ }^{448} \text { NITGLLLT } \\
\text { RD-GGT }{ }^{456 / 462} \text { ins } 459 a=T\end{array}$ & 0.78 & $\mathrm{~m} \downarrow$ \\
\hline $\begin{array}{l}469 \\
{ }^{463} N D T E V F R P G G G \\
473\end{array}$ & 1.11 & - \\
\hline $\begin{array}{l}476 \\
{ }^{463}{ }^{2} \text { DTEVFRPGGGDMR } \\
\end{array}$ & 0.40 & $\mathbf{s} \downarrow$ \\
\hline $\begin{array}{l}480 \\
477 \text { DNWRSE LYK }\end{array}$ & 0.25 & $\mathbf{s} \downarrow$ \\
\hline
\end{tabular}

${ }^{a}$ Italicized $\mathrm{N}$ indicates that this residue was originally glycosylated. ${ }^{\mathrm{b}} \mathrm{m}$ = moderate (between 1 and 2 standard deviations; $\mathrm{s}=$ strong (greater than two standard deviations); - = no significant change.

'Two peptides were found that included R252, one starting with AA 237 and the second starting with AA241.

dTwo peptides were found that included R456, one ending with AA 456 and the second ending with AA459a ins.

one missed cleavage arising from combined trypsin and GluC proteolysis. This peptide also contained R469. R469 was also observed by itself in peptide 463-473, in which no change in extent of modification to R469 was observed between bound and unbound gp120. Thus, changes in the relative extent of modification between bound and unbound gp120 peptide 463-476 was attributed to changes in the extent of modification to R476. Peptides containing 13 of 25 arginine residues were observed whose sequences were confirmed by MS/MS.

\section{R456, R476, and R480}

The reactivity of these residues were significantly reduced (by more than one standard deviation) in the presence of 559/64-D, with R476 and 480 being most strongly affected. The reactivity of R456 is less strongly affected by the presence of the Ab (Figure 3, Supplemental Figure S-2). These residues are in the protein core of gp120 (Figure 4a). It should be noted that R456 was observed in several peptides after PNGase F treatment, 448-456, 448-459 ins 459a $=\mathrm{T}$ (one missed cleavage site) and 448-462 ins $459 \mathrm{a}=\mathrm{T}$ (two missed cleavage sites). The unmodified peptide dominated in all cases. Peptide 448-462 ins 459a $=\mathrm{T}$ contains a glycosylation site at N460 that is only partially glycosylated [11]. During deglycosylation with PNGaseF the glycosylated asparagine residue will be transformed to an aspartic acid residue, while the asparagine residue of the nonglycosylated peptide will not be affected. Peptide 448462 ins $459 \mathrm{a}=\mathrm{T}$ with $\mathrm{N} 460$ and peptide 448-462 ins $459 \mathrm{a}=\mathrm{T}$ with $\mathrm{D} 460$ could be separated by $0.23 \mathrm{~min}$ by reversed-phase chromatography. The sequence of these peptides was confirmed by MS/MS (data not shown). For all peptides, the ratios of modified to unmodified peptides in the bound and unbound forms showed moderate protection.

\section{R59}

The reactivity of $\mathrm{R} 59$ is moderately increased in the presence of the Ab. The position of R59 in the gp120 structure was not determined in the solved structure of the construct, which did not include the first $52 \mathrm{~N}$ terminal residues. It was also omitted from our computational model of $\mathrm{HIV}_{\mathrm{SF} 2}$ gp120 [9, 12]. Our results, however, indicate that this residue is slightly more accessible in the presence of MAb 559/64-D.

\section{R252}

This arginine exhibited slightly lower reactivity when bound to the antibody. R252 is located spatially close to A287 of the V3 loop. The slightly increased protection of this residue may be due to movement of the V3 loop and/or glycans upon $\mathrm{Ab}$ binding.

R166, 177, 273, 298, 335, 395a, 419, and 469

The relative reactivities of these arginines did not vary significantly from the mean. Thus, the locations of these residues are such that the reactivities are unaffected by the presence of the antibody.

Peptides for the remaining 12 arginine residues were not observed. One possible reason for this is the size of the peptides formed during proteolysis may be too small or too large to be analyzed. Blocked cleavage at acetylated lysine can lead to large peptides. For example, a complete digest of gp120 with LysC/AspN would result in arginine-containing peptides with a mass smaller than $600 \mathrm{Da}$, and trypsin/Glu-C digestion can still lead to peptides with a mass of over $4000 \mathrm{Da}$ containing two arginine residues. In summary, 13 of 25 arginine residues were characterized, and five of these were affected by the binding of 559/64-D. 


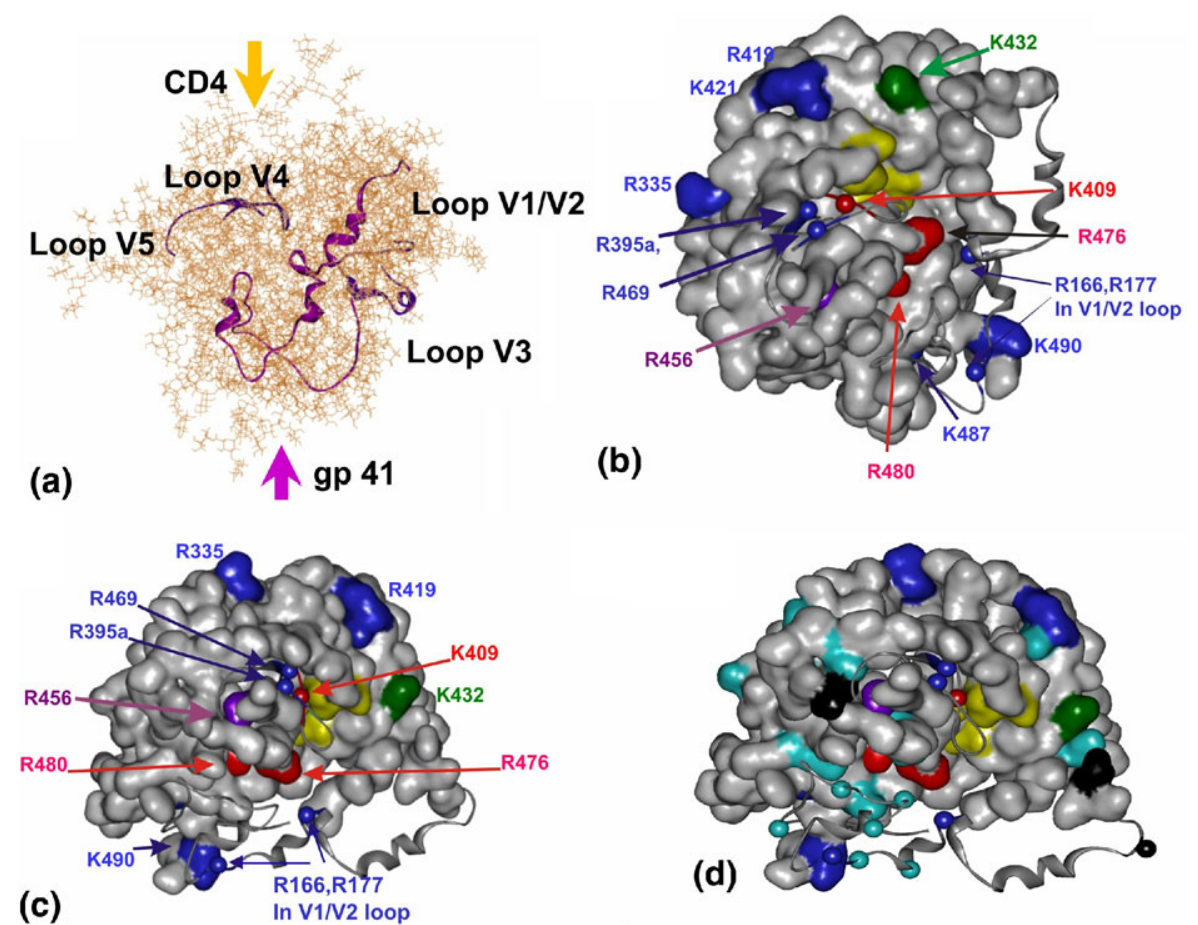

Figure 4. (a) The structural model of glycosylated full-length gp120 of HIV strain SF2 as determined by Zhu et al. [12] was used to depict the protein core (gray ribbon), the variable loops (blue and purple ribbons), and the glycan chains (stick models). The model is oriented with the gp41-interaction site on the bottom of gp120 (purple arrow) and CD4 entering its binding site from the top (gold arrow). (b) The amino acids characterized in this study were mapped to $\mathrm{HIV}_{\mathrm{SF} 2}$ gp120 with the protein core as a surface model and the loops as ribbons. Residues with a significantly decreased relative reactivity are shown in red, residues with a slightly decreased relative reactivity are shown in purple, residues with no change in relative reactivity in blue, and residues with an increase in relative reactivity are shown in dark-green. Amino acids in light-yellow reside within the CD4 binding area as found in the X-ray structure of $\mathrm{HIV}_{\mathrm{HXBc2}}$ gp120 [9]. The orientation is the same as in (a). (c) The gp120-model was tilted $90^{\circ}$ forwards such that an interacting CD4-molecule would stick out of the paper plane and gp41 would be located "behind" gp120. Color code is as in (b). (d) Same view as in (c) with all lysines and arginines, which were not verifiably detected in these experiments colored in cyan and black, respectively.

\section{Structural Implications-Localization in the Three-Dimensional Structure of gp120}

Based on the high sequence homology between HIV strains SF2 and HXBc2 (see Figure 1), the structural data of the gp120 core of $\mathrm{HIV}_{\mathrm{HXBc2}}$ [9], and the characterization of the glycan chains of recombinantly expressed $\mathrm{HIV}_{\mathrm{SF} 2}$ gp120, a molecular model of glycosylated fulllength gp120 was developed (Figure 4a) [12]. The model is depicted to illustrate the extensive shielding of the gp120 core by the carbohydrate moieties and the position of the variable loops V1/V2, V3, V4, and V5. Using this model, localization of the residues characterized in this study is shown in Figure $4 \mathrm{~b}$ (same orientation as in Figure 4a) and in Figure 4c (gp120 tilted forwards by $90^{\circ}$ ), omitting the glycans for clarity. The amino acids for which the relative reactivity was significantly reduced by the presence of the MAb form a cluster around the CD4-binding site, predominantly on one side of the CD4-BS cleft, and are indicative of the epitope recognized by the MAb 559/64-D. The MAbshielded residues R456, R476 and R480 are located in the core of gp120 (as modeled as the surface described in the caption of Figure 4), whereas K409 is within the flexible loop V4, but within $8.8 \AA$ of the significantly affected R456 (C $\alpha$-atoms).

The position of residues R59, K500, and K502 could not be determined because 52 residues at the $\mathrm{N}$-terminus and 19 residues at the C-terminus of the HIVHXBc2 gp120 core were deleted for the crystallization studies and were also omitted from the computational model of the $\mathrm{HIV}_{\mathrm{SF} 2}$ gp120 $[9,12]$. However, all additional residues characterized in this study are exposed on the protein surface.

The amino acids characterized in this study were also mapped on the structure of the SIVgp120 core, which was crystallized in the absence of interacting proteins such as CD4 or Abs [27, 44]. Residues I469, A486, and R490 corresponding to the significantly affected residues R456, R476, and R480 in the HIVHXBc2 env-protein [27] are located within or in the vicinity of the CD4-interaction site (Figure 5a, same orientation as for Figure $4 \mathrm{a}$ ), and the distances between these residues 


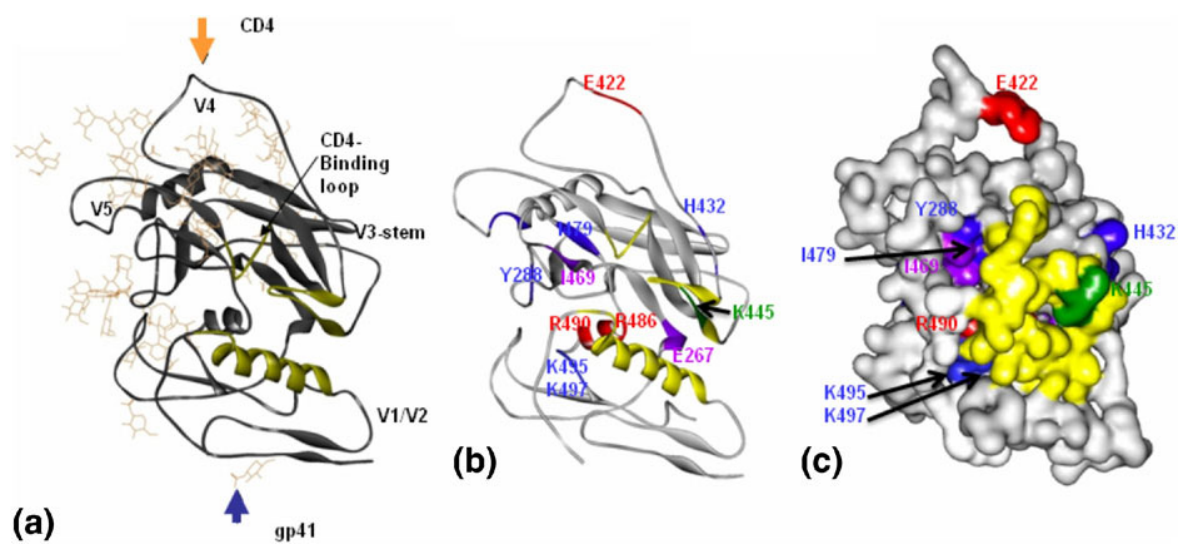

Figure 5. (a) The structure of the glycosylated unliganded SIV gp120-core [32] is shown with the protein core as gray ribbon and the carbohydrate moieties as tan stick models. The orientation is the same as for the HIV gp120 core in Figure 4A. (b) Amino acids at the same position in the linear sequence corresponding to the residues characterized in this study were mapped to the ribbon model of the SIV gp120 core. (c) Amino acids corresponding to the residues characterized in this study were mapped to the surface model of the SIV gp120 core. The color code of the relative reactivity of residues affected by the MAb 559/64-D is as in Figure 4.

are similar to the distances determined for $\mathrm{HIV}_{\mathrm{HXBc2}}$

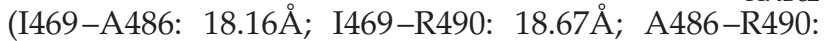
$5.55 \AA$ between $C \alpha$-atoms). However, in the crystal structure these residues are partly covered by the residues $\mathrm{N}$-terminal of the helix $\alpha 1$ (Figure $5 \mathrm{c}$ ). Stricher et al. recently studied the structural basis of immune evasion at the CD4-BS on HIV-1 gp120 and found that several antibodies recognize the CD4-BS, but are not broadly neutralizing, and these less broadly neutralizing antibodies assumed a conformation that was poorly compatible with the functional trimeric viral spike [24].

Although neutralizing antibodies such as 2F5 can recognize a linear protein-based epitope on the envprotein [45-47] (though the linear peptide corresponding to the epitope cannot generate neutralizing antibodies), the majority of broadly neutralizing antibodies recognize conformational (e.g., 2F5) and/or discontinuous epitopes ([1, 14, 20] and references therein). According to the distribution of the amino acids in the linear sequence of gp120, the residues with decreased relative reactivity for derivatizing agents upon binding of the MAb 559/64-D, the epitope recognized by this neutralizing $\mathrm{Ab}$ is also discontinuous. Based on the crystal structure of the gp120 core from the HIV strain HXBc2 $[9,45]$ and the assignment of the immunogenic areas "neutralizing face," "non-neutralizing face," and "silent face" [17, 20], the MAb 559/64-D binds to the CD4-BS within the neutralizing face on gp120 as inferred from the significantly reduced reactivity of K409, R456, R476, and R480. The structure of the Fab fragment of MAb F105, another broadly neutralizing Ab that does not neutralize primary isolates, has been published and its interaction with the gp120 CD4-BS has been modeled [36]. The MAb was predicted to interact with residues 255-7, 368, 370, 375, 384, 421, 470, and 473-477. Our results indicate that 559/64-D binds in a similar, but not identical, manner in that R476 and 480 are significantly affected by the $\mathrm{Ab}$, but $\mathrm{R} 469$ is not. In contrast, the broadly neutralizing MAb b12 does not interact with residues 473-476 (the $\mathrm{N}$-terminal end of helix $\alpha 5$ ), consistent with the hypothesis that interactions with residues $473-477$ may be a major difference between antibodies recognizing primary isolates and those recognizing gp120 epitopes on TCLA strain [36].

As discussed previously, differences in the environment of specific residues, e.g., salt bridges, can lead to differences in reactivity not directly associated with surface reactivity (see, for example, [40, 48]). Conformational changes have been similarly invoked to explain changes in differential reactivity of specific residues [49]. Experimental evidence from a number of researchers indicates that gp120 undergoes a conformational change upon CD4 binding [24, 50-53] and upon binding of certain antibodies [25]. Our results also implicate conformational effects on our differential surface modification data. As residues distant from the CD4-BS were also affected, this approach to epitope mapping is also sensitive to factors that affect surface reactivity in addition to direct interaction between the antigen and the antibody. The complexity of the glycoprotein gp120 may complicate the differential reactivity approach to epitope mapping in various ways. Due to the extensive glycosylation of gp120, steric hindrance for the derivatizing agent might lead to reduced reactivity of amino acids, which do not interact with the Ab. In addition, $\mathrm{Ab}$ binding to the CD4-BS might induce conformational changes of the gp120 core, which results in newly formed intermolecular interaction sites. Although the reduced accessibilities of these residues would be specific for the Ab-bound conformation they would not be indicative of the intermolecular interaction site between $\mathrm{Ab}$ and antigen. Indeed, using a similar approach, we have observed significant changes between chemical reactivity in HCV E2 glycoprotein in the presence and 
absence of an $\mathrm{Ab}$ that can only be explained by significant Ab-induced conformational changes [49]. However, comparison of the results obtained for the epitope of the MAb 559/64-D and reports for epitopes of other Abs in the literature show the validity of our approach for epitope mapping using glycosylated full-length gp120 [44, 46].

In summary, we conclude from our experiments of chemical modification of lysine and arginine residues followed by mass spectrometric analyses that the epitope recognized by the MAb 559/64-D overlaps the CD4binding site of gp120. Moreover, binding of the MAb to its antigen seems to have an effect on the conformation of gp120.

As mentioned above, modifications of residues that lead to change of the formal charge on the residue side chain may also influence the solubility of the modified protein, leading to reduced information about the reactivity of some residues. We are currently investigating alternative derivatizing reagents to circumvent this problem.

\section{Acknowledgments}

The authors acknowledge support in part for this research by the Intramural Research Program of the National Institute of Environmental Health Sciences/National Institutes of Health (z050150) and the NIH/NHLBI (grant HL59725 to S.Z.-P).

\section{Appendix A Supplementary Material}

Supplementary material associated with this article may be found in the online version at doi:10.1016/ j.jasms.2010.03.031.

\section{References}

1. Zolla-Pazner, S. Identifying Epitopes of HIV-1 that Induce Protective Antibodies. Nature Reviews Immunology 2004, 4(3), 199-210.

2. Poignard, P.; Klasse, P. J.; Sattentau, Q. J. Antibody Neutralization of HIV-1. Immunol. Today 1996, 17(5), 239-246.

3. Center, R. J.; Leapman, R. D.; Lebowitz, J.; Arthur, L. O.; Earl, P. L.; Moss, B. Oligomeric Structure of the Human Immunodeficiency Virus Type I Envelope Protein on the Virion Surface. J. Virol. 2002, 76(15), 7863-7867.

4. Dalgleish, A. G.; Beverley, P. C. L.; Clapham, P. R.; Crawford, D. H.; Greaves, M. F.; Weiss, R. A. The CD4 (T4) Antigen is an Essential Component of the Receptor for the AIDS Retrovirus. Nature 1984, 312(5996), 763-767.

5. Klatzmann, D.; Champagne, E.; Chamaret, S.; Gruest, J.; Guetard, D.; Hercend, T.; Gluckman, J. C.; Montagnier, L. Lymphocyte-T T4 Molecule Behaves as the Receptor for Human Retrovirus LAV. Nature 1984, 312(5996), 767-768.

6. Gagne, N. Demonstration of a Thermoreversible Gel for the Prevention of HIV and Herpes Transmission; Universite Laval: QC, Canada 2000; p. 111.

7. Zaitseva, M.; Peden, K.; Golding, H. HIV Coreceptors: Role of Structure, Post-Translational Modifications, and Internalization in Viral-Cell Fusion and as Targets for Entry Inhibitors. Biochim. Biophys. Acta-Biomembranes 2003, 1614(1), 51-61.

8. Starcich, B. R.; Hahn, B. H.; Shaw, G. M.; McNeely, P. D.; Modrow, S.; Wolf, H.; Parks, E. S.; Parks, W. P.; Josephs, S. F.; Gallo, R. C.; Wongstaal, F. Identification and Characterization of Conserved and Variable Regions in the Envelope Gene of HTLV-III LAV, the Retrovirus of AIDS. Cell 1986, 45(5), 637-648.

9. Kwong, P. D.; Wyatt, R.; Robinson, J.; Sweet, R. W.; Sodroski, J.; Hendrickson, W. A. Structure of an HIV gp120 Envelope Glycoprotein in Complex with the CD4 Receptor and a Neutralizing Human Antibody. Nature 1998, 393(6686), 648-659.
10. Leonard, C. K.; Spellman, M. W.; Riddle, L.; Harris, R. J.; Thomas, J. N.; Gregory, T. J. Assignment of Intrachain Disulfide Bonds and Characterization of Potential Glycosylation Sites of the Type-1 Recombinant Human-Immunodeficiency-Virus Envelope Glycoprotein (gp120) Expressed in Chinese Hamster Ovary Cells. J. Biol. Chem. 1990, 265(18), 10373-10382.

11. Cutalo, J. M.; Deterding, L. J.; Tomer, K. B. Characterization of Glycopeptides from HIV-I-SF2 gp120 by Liquid Chromatography Mass Spectrometry. J. Am. Soc. Mass Spectrom. 2004, 15(11), 1545-1555.

12. Zhu, X. G.; Borchers, C.; Bienstock, R. J.; Tomer, K. B. Mass Spectrometric Characterization of the Glycosylation Pattern of HIV-gp120 Expressed in CHO cells. Biochemistry 2000, 39(37), 11194-11204.

13. Bouma, P.; Leavitt, M.; Zhang, P. F.; Sidorov, I. A.; Dimitrov, D. S. Quinnan, G. V. Multiple Interactions Across the Surface of the gp120 Core Structure Determine the Global Neutralization Resistance Phenotype of Human Immunodeficiency Virus Type 1. J. Virol. 2003, 77(14), 8061-8071.

14. Gorny, M. K.; Williams, C.; Volsky, B.; Revesz, K.; Cohen, S.; Polonis, V. R.; Honnen, W. J.; Kayman, S. C.; Krachmarov, C.; Pinter, A.; Zolla-Pazner, S. Human Monoclonal Antibodies Specific for ConformationSensitive Epitopes of V3 Neutralize Human Immunodeficiency Virus Type 1 Primary Isolates from Various Clades. J. Virol. 2002, 76(18), 9035-9045.

15. Moore, J. P.; Sodroski, J. Antibody Cross-Competition Analysis of the Human Immunodeficiency Virus Type 1 gp120 Exterior Envelope Glycoprotein. I. Virol. 1996, 70(3), 1863-1872.

16. Nyambi, P. N.; Mbah, H. A.; Burda, S.; Williams, C.; Gorny, M. K Nadas, A.; Zolla-Pazner, S. Conserved and Exposed Epitopes on Intact, Native, Primary Human Immunodeficiency Virus Type 1 Virions of Group M. J. Virol. 2000, 74(15), 7096-7107.

17. Wyatt, R.; Sodroski, J.; The HIV-1 Envelope Glycoproteins: Fusogens, Antigens, and Immunogens. Science 1998, 280(5371), 1884-1888.

18. Zwick, M. B.; Kelleher, R.; Jensen, R.; Labrijn, A. F.; Wang, M.; Quinnan, G. V.; Parren, P.; Burton, D. R. A Novel Human Antibody Against Human Immunodeficiency Virus Type 1 gp120 is V1, V2, and V3 Loop Dependent and Helps Delimit the Epitope of the Broadly Neutralizing Antibody Immunoglobulin G1 b12. J. Virol. 2003, 77(12), 6965-6978.

19. Zwick, M. B.; Parren, P.; Saphire, E. O.; Church, S.; Wang, M.; Scott, J. K.; Dawson, P. E.; Wilson, I. A.; Burton, D. R. Molecular Features of the Broadly Neutralizing Immunoglobulin G1 b12 Required for Recognition of Human Immunodeficiency Virus Type 1 gp120. J. Virol. 2003, 77(10), 5863-5876.

20. Wyatt, R.; Kwong, P. D.; Desjardins, E.; Sweet, R. W.; Robinson, J.; Hendrickson, W. A.; Sodroski, J. G. The Antigenic Structure of the HIV gp120 Envelope Glycoprotein. Nature 1998, 393(6686), 705-711.

21. Nunberg, J. H.; Follis, K. E.; Trahey, M.; LaCasse, R. A. Turning a corner on HIV neutralization? Microb. Infect. 2000, 2(2), 213-221.

22. Myszka, D. G.; Sweet, R. W.; Hensley, P.; Brigham-Burke, M.; Kwong, P. D.; Hendrickson, W. A.; Wyatt, R.; Sodroski, J.; Doyle, M. L. Energetics of the HIV gp120-CD4 Binding Reaction. Proc. Natl. Acad. Sci. U.S.A. 2000, 97(16), 9026-9031.

23. Xiang, S. H.; Kwong, P. D.; Gupta, R.; Rizzuto, C. D.; Casper, D. J.; Wyatt, R.; Wang, L. P.; Hendrickson, W. A.; Doyle, M. L.; Sodroski, J. Mutagenic Stabilization and/or Disruption of a CD4-Bound State Reveals Distinct Conformations of the Human Immunodeficiency Virus Type 1 gp120 Envelope Glycoprotein. J. Virol. 2002, 76(19), 9888-9899.

24. Stricher, F.; Huang, C. C.; Descours, A.; Duquesnoy, S.; Combes, O.; Decker, J. M.; Do Kwon, Y.; Lusso, P.; Shaw, G. M.; Vita, C.; Kwong, P. D.; Martin, L. Combinatorial Optimization of a CD4-Mimetic Miniprotein and Cocrystal Structures with HIV-1 gp120 Envelope Glycoprotein. J. Mol. Biol. 2008, 382(2), 510-524.

25. Chen, L.; Kwon, Y. D.; Zhou, T. Q.; Wu, X. L.; O’Dell, S.; Cavacini, L.; Hessell, A. J.; Pancera, M.; Tang, M.; Xu, L.; Yang, Z. Y.; Zhang, M. Y.; Arthos, J.; Burton, D. R.; Dimitrov, D. S.; Nabel, G. J.; Posner, M. R.; Sodroski, J.; Wyatt, R.; Mascola, J. R.; Kwong, P. D. Structural Basis of Immune Evasion at the Site of CD4 Attachment on HIV-1 gp120. Science 2009, 326(5956), 1123-1127.

26. Pan, Y. P.; Ma, B. Y.; Keskin, O.; Nussinov, R. Characterization of the Conformational State and Flexibility of HIV-1 Glycoprotein gp120 Core Domain. J. Biol. Chem. 2004, 279(29), 30523-30530.

27. Chen, B.; Vogan, E. M.; Gong, H. Y.; Skehel, J. J.; Wiley, D. C.; Harrison, S. C. Structure of an Unliganded Simian Immunodeficiency Virus gp120 Core. Nature 2005, 433(7028), 834-841.

28. McKeating, J. A.; Thali, M.; Furman, C.; Karwowska, S.; Gorny, M. K. Cordell, J.; Zolla-Pazner, S.; Sodroski, J.; Weiss, R. A. Amino Acid Residues of the Human Immunodeficiency Virus Type I gp120Ccritical for the Binding of Rat and Human Neutralizing Antibodies that Block the gp120-sCD4 Interaction. Virology 1992, 190(1), 134-142.

29. Karwowska, S.; Gorny, M. K.; Buchbinder, A.; Gianakakos, V.; Williams C.; Fuerst, T.; Zolla-Pazner, S. Production of Human Monoclonal Antibodies Specific for Conformational and Linear Non-V3 Epitopes of gp120. AIDS Res. Hum. Retrovir. 1992, 8(6), 1099-1106.

30. Chien, P. C.; Cohen, S.; Tuen, M.; Arthos, J.; Chen, P. D.; Patel, S.; Hioe, C. E. Human Immunodeficiency Virus Type 1 Evades T-Helper Responses by Exploiting Antibodies that Suppress Antigen Processing. J. Virol. 2004, 78(14), 7645-7652.

31. Li, H. L.; Chien, P. C.; Tuen, M.; Visciano, M. L.; Cohen, S.; Blais, S.; Xu, C. F.; Zhang, H. T.; Hioe, C. E. Identification of an N-Linked Glycosylation in the C4 Region of HIV-1 Envelope gp120 that is Critical for Recognition of Neighboring CD4 T Cell Epitopes. J. Immunol. 2008, 180(6), 4011-4021. 
32. Li, H. L.; Xu, C. F.; Blais, S.; Wan, Q.; Zhang, H. T.; Landry, S. J.; Hioe, C. E. Proximal Glycans Outside of the Epitopes Regulate the Presentation of HIV-1 Envelope gp120 Helper Epitopes. J. Immunol. 2009, 182(10), 6369-6378

33. Visciano, M. L.; Tuen, M.; Gorny, M. K.; Hioe, C. E. In Vivo Alteration of Humoral Responses to HIV-1 Envelope Glycoprotein gp120 by Antibodies to the CD4-Binding Site of gp120. Virology 2008, 372(2), $409-420$.

34. Nandi, A.; Lavine, C. L.; Wang, P. C.; Lipchina, I.; Goepfert, P. A.; Shaw, G. M.; Tomaras, G. D.; Montefiori, D. C.; Haynes, B. F.; Easterbrook, P.; Robinson, J. E.; Sodroski, J. G.; Yang, X. Z.; and the NIAID Center for HIV / AIDS Vaccine Immunology. Epitopes for Broad and Potent Neutralizing Antibody Responses During Chronic Infection with Human Immunodeficiency Virus Type 1. Virology 2010, 396(2), 339-348.

35. Stamatatos, L.; Chengmayer, C. Structural Modulations of the Envelope gp120 Glycoprotein of Human-Immunodeficiency-Virus Type-1 Upon Oligomerization and Differential V3 Loop Epitope Exposure of Isolates Displaying Distinct Tropism Upon Virion-Soluble Receptor-Binding. J. Virol. 1995, 69(10), 6191-6198.

36. Wilkinson, R. A.; Piscitelli, C.; Teintze, M.; Cavacini, L. A.; Posner, M. R.; Lawrence, C. M.; Structure of the Fab Fragment of F105, a Broadly Reactive Anti-Human Immunodeficiency Virus (HIV) Antibody that Recognizes the CD4 Binding Site of HIV Type 1 gp120. J. Virol. 2005, 79(20), 13060-13069.

37. Glocker, M. O.; Borchers, C.; Fiedler, W.; Suckau, D.; Przybylski, M. Molecular Characterization of Surface-Topology in Protein Tertiary Structures by Aminoacylation and Mass-Spectrometric Peptide Mapping. Bioconj. Chem. 1994, 5(6), 583-590.

38. Hochleitner, E. O.; Borchers, C.; Parker, C.; Bienstock, R. J.; Tomer, K. B. Characterization of a Discontinuous Epitope of the Human Immunodeficiency Virus (HIV) Core Protein p24 by Epitope Excision and Differential Chemical Modification Followed by Mass Spectrometric Peptide Mapping Analysis. Protein Sci. 2000, 9(3), 487-496.

39. Steiner, R. F.; Albaugh, S.; Fenselau, C.; Murphy, C.; Vestling, M. A Mass-Spectrometry Method for Mapping the Interface Topography of Interacting Proteins, Illustrated by the Melittin-Calmodulin System. Anal. Biochem. 1991, 196(1), 120-125.

40. Suckau, D.; Mak, M.; Przybylski, M. Protein Surface Topology-Probing by Selective Chemical Modification and Mass-Spectrometric Peptide Mapping. Proc. Natl. Acad. Sci. U.S.A. 1992, 89(12), 5630-5634.

41. Hager-Braun, C.; Tomer, K. B. Characterization of the Tertiary Structure of Soluble CD4 Bound to Glycosylated Full-Length HIVgp120 by Chemical Modification of Arginine Residues and Mass Spectrometric Analysis. Biochemistry 2002, 41(6), 1759-1766.

42. Wood, T. D.; Guan, Z. Q.; Borders, C. L.; Chen, L. H.; Kenyon, G. L.; McLafferty, F. W. Creatine Kinase: Essential Arginine Residues at the Nucleotide Binding Site Identified by Chemical Modification and High-Resolution Tandem Mass Spectrometry. Proc. Natl. Acad. Sci. U.S.A. 1998, 95(7), 3362-3365.
43. Korber, B. T.; Foley, B. T.; Kuiken, C. L.; Pillai, S. K.; Sodroski, J. G. Numbering Positions in HIV Relative to HXB2CG. 1998 [cited 1998; available from: http:/ / www.hiv.lanl.gov/content/sequence/HIV/COMPENDIUM/1998/ III/HXB2.pdf.

44. Hager-Braun, C.; Katinger, H.; Tomer, K. B. The HIV-Neutralizing Monoclonal Antibody 4E10 Recognizes N-Terminal Sequences on the Native Antigen. J. Immunol. 2006, 176(12), 7471-7481.

45. Kwong, P. D.; Wyatt, R.; Majeed, S.; Robinson, J.; Sweet, R. W.; Sodroski, J.; Hendrickson, W. A. Structures of HIV-1 gp120 Envelope Glycoproteins from Laboratory-Adapted and Primary Isolates. Structure 2000, 8(12), 1329-1339.

46. Parker, C. E.; Deterding, L. J.; Hager-Braun, C.; Binley, J. M.; Schulke, N.; Katinger, H.; Moore, J. P.; Tomer, K. B. Fine Definition of the Epitope on the gp41 Glycoprotein of Human Immunodeficiency Virus Type 1 for the Neutralizing Monoclonal Antibody 2F5. J. Virol. 2001, 75(22), 10906-10911.

47. Zwick, M. B.; Labrijn, A. F.; Wang, M.; Spenlehauer, C.; Saphire, E. O.; Binley, J. M.; Moore, J. P.; Stiegler, G.; Katinger, H.; Burton, D. R.; Parren, P. Broadly Neutralizing Antibodies Targeted to the MembraneProximal External Region of Human Immunodeficiency Virus Type 1 Glycoprotein gp41. J. Virol. 2001, 75(22), 10892-10905.

48. Hobbs, C. A.; Deterding, L. J.; Perera, L.; Bobay, B. G.; Thompson, R. J.; Darden, T. A.; Cavanagh, J.; Tomer, K. B. Structural Characterization of the Conformational Change in Calbindin-D-28k upon Calcium Binding Using Differential Surface Modification Analyzed by Mass Spectrometry. Biochemistry 2009, 48(36), 8603-8614.

49. Iacob, R. E.; Keck, Z.; Olson, O.; Foung, S. K. H.; Tomer, K. B. Structural Elucidation of Critical Residues Involved in Binding of Human Monoclonal Antibodies to Hepatitis C Virus E2 Envelope Glycoprotein Biochim. Biophys. Acta-Proteins and Proteomics 2008, 1784(3), 530-542.

50. Feng, Y.; Broder, C. C.; Kennedy, P. E.; Berger, E. A. HIV-1 Entry Cofactor: Functional cDNA Cloning of a Seven-Transmembrane, G Protein-Coupled Receptor. Science 1996, 272(5263), 872-877.

51. Lusso, P.; HIV and the Chemokine System: 10 Years Later. EMBO J. 2006, 25(3), 447-456.

52. Trkola, A.; Dragic, T.; Arthos, J.; Binley, J. M.; Olson, W. C.; Allaway, G. P.; ChengMayer, C.; Robinson, J.; Maddon, P. J.; Moore, J. P. CD4-Dependent, Antibody-Sensitive Interactions Between HIV-1 and Its Coreceptor CCR-5. Nature 1996, 384(6605), 184-187.

53. Wu, L. J.; Gerard, N. P.; Wyatt, R.; Choe, H.; Parolin, C.; Ruffing, N.; Borsetti, A.; Cardoso, A. A.; Desjardin, E.; Newman, W.; Gerard, C. Sodroski, J. CD4-Induced Interaction of Primary HIV-1 gp120 Glycoproteins with the Chemokine Receptor CCR-5. Nature 1996, 384(6605), $179-183$.

54. Sanchezpescador, R.; Power, M. D.; Barr, P. J.; Steimer, K. S.; Stempien, M. M.; Brownshimer, S. L.; Gee, W. W.; Renard, A.; Randolph, A.; Levy, J. A.; Dina, D.; Luciw, P. A. Nucleotide Sequence and Expression of an AIDS-Associated Retrovirus (ARV-2). Science 1985, 227(4686), 484-492. 